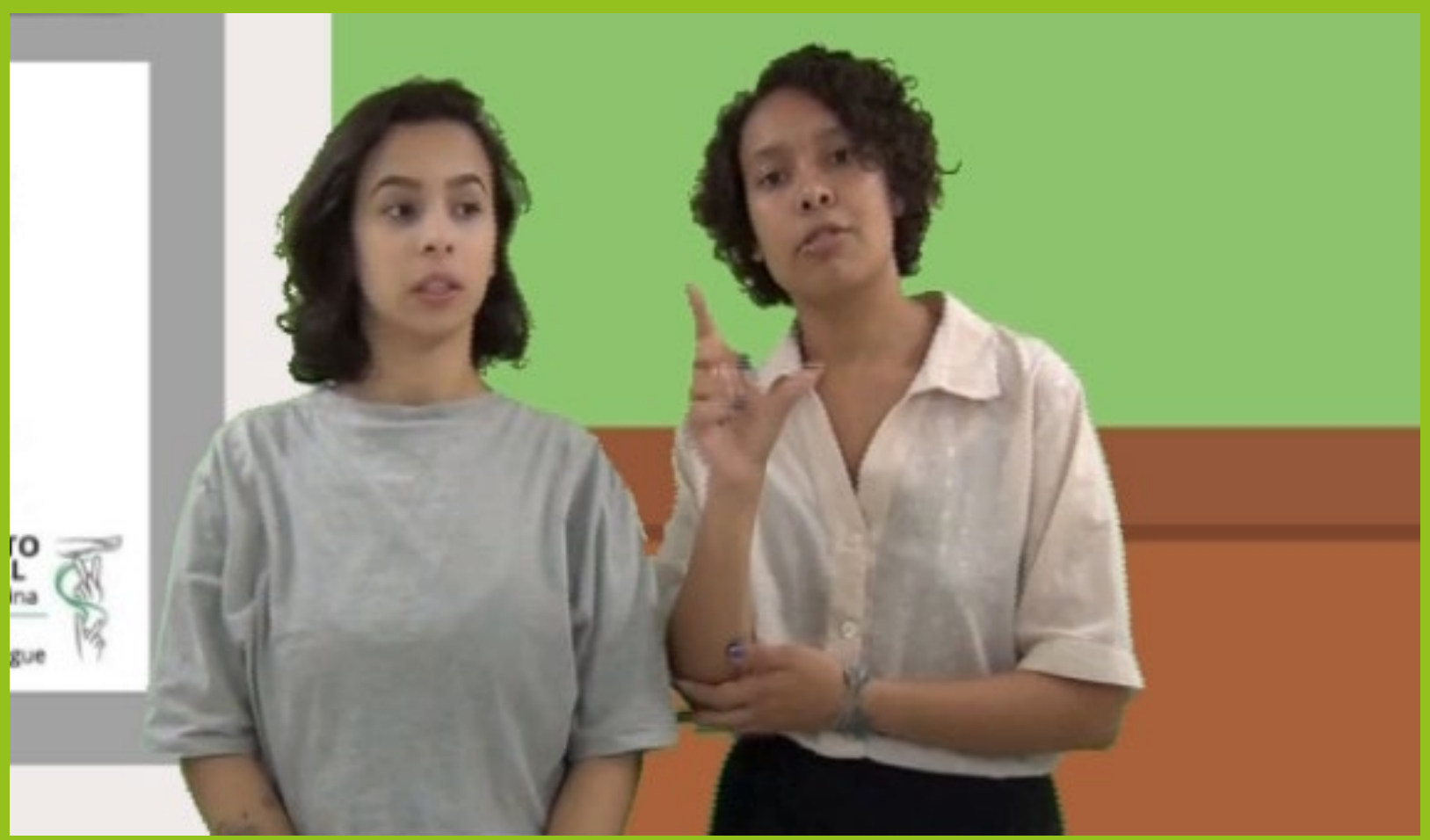

\title{
Educação sexual para
} prevenir abusos: socializando visualmente conhecimentos em língua brasileira de sinais

\section{Saionara Figueiredo Santos ${ }^{1}$}

saionara.figueiredo@ifsc.edu.br

\section{Ana Carolina Bitencourt ${ }^{2}$}

anacalopesbiten@gmail.com

\section{Heitor Ramos ${ }^{3}$}

heitorgpramos95@gmail.com

\section{Joana Vianna ${ }^{4}$}

joana.vnn@gmail.com

1 Doutora em Estudos da Tradução. Professora de Tradução no IFSC, Câmpus Palhoça Bilíngue.

2 Graduanda em Pedagogia Bilíngue, pelo IFSC, Campus Palhoça Bilíngue.

3 Graduando em Pedagogia Bilíngue, pelo IFSC, Campus Palhoça Bilíngue.

4 Graduanda em Pedagogia Bilíngue, pelo IFSC, Campus Palhoça Bilíngue. 


\section{RESUMO}

Este artigo propõe-se a socializar os resultados obtidos através do projeto de extensão intitulado "Sexualidade e segurança: oficinas e palestras sobre educação sexual para jovens surdos da Grande Florianópolis", com financiamento do Instituto Federal de Santa Catarina, através do EDITAL PROEX no 16/2018 Protagonismo discente. Este projeto teve como objetivo principal informar adolescentes surdos acerca de questões relacionadas aos estudos de Gênero e Sexualidade e toda sua amplitude. Conseguimos neste projeto articular a temática da surdez com discussões referentes a gênero e sexualidade, tomando por referência autores da perspectiva dos Estudos Culturais em Educação e dos Estudos Surdos. No nosso caso, essas temáticas foram entendidas a partir da diferença cultural. Nos propusemos a criar uma mídia escrita e em vídeo que auxiliassem a exposição desta linha de conhecimentos. Os alunos tiveram oportunidade de entender a relação ensino/pesquisa/extensão, bem como entender como a pedagogia de ensino é diferente no contexto de outra língua espaço-visual. Tais mídias já foram compartilhadas com a comunidade e acreditamos que conseguimos colaborar, no contexto bilíngue, na difusão de conhecimentos sobre Gênero e Sexualidade. Ainda assim, também incentivamos que novas pesquisas e novos materiais precisam ser criados nesta temática, já que é um contexto amplo e ainda pouco abordado no ínterim das comunidades surdas.

Palavras-chave: Surdos. Gênero. Sexualidade. Pesquisa.

This article proposes to share the results obtained in this project: "Sexuality and safety: workshops and lectures on sexual education for young deaf students in Florianópolis", with funding from the Federal Institute of Santa Catarina, through PROEX EDITAL no. 16 / 2018. This project had as main objective to inform deaf adolescents about issues related to the studies of Gender and Sexuality and all its amplitude. We succeeded in this project to articulate the theme of deafness with discussions regarding gender and sexuality, taking as reference authors from the perspective of Cultural Studies in Education and Deaf Studies. In our case, these themes were understood from the cultural difference. We set out to create written and video medias that would help expose gender and sexuality knowledge. The students had the opportunity to understand the teaching/researching / extension relationship, as well as to understand how teaching pedagogy is different in the context of another space-visual language. Such media have already been shared with the community and we believe that we have been able to collaborate, in the bilingual context, in the dissemination of knowledge on Gender and Sexuality. Nevertheless, we also encourage that new research and new materials need to be created in this area, since it is a broad context and still little addressed in the interim of the deaf communities. Keywords: Deaf. Gender. Sexuality. Research.

\section{Introdução}

0 presente artigo surge como socialização dos resultados obtidos com o projeto de extensão intitulado "Sexualidade e segurança: oficinas e palestras sobre educação sexual para jovens surdos da Grande Florianópolis", com financiamento do Instituto Federal de Santa Catarina, através do Edital Proex no $16 / 2018$ (Protagonismo discente). Este projeto teve como objetivo principal informar adolescentes surdos acerca de questões relacionadas aos estudos de gênero e sexualidade e toda sua amplitude.

A necessidade de projetos com essa temática é emergente, já que combinar categorias como gênero e pessoas surdas ainda é um enlace pouco aprofundado. Não há muitos estudos que trabalhem dados empíricos que unam a questão de gênero e sexualidade, já que tal questão ainda começa a ser problematizada nas pautas de reivindicações surdas. Assim, propondo uma discussão que englobe estas propostas, conseguem-se aproximações com estudos feministas que produzem trabalhos através de uma "perspectiva pós-estruturalista, problematizando o gênero feminino através da diferença" (KLEIN; DE PAULA FORMOZO, 2007, p. 101).

Num câmpus onde a Língua Brasileira de Sinais (Libras) é levada em conta no projeto didático pedagógico, todos os alunos possuem contato com essa diversidade. A partir do contato com a pedagogia 
da diferença ${ }^{5}$, na qual está estruturada a proposta epistemológica do câmpus acima citado, os alunos conseguem se inserir na cultura surda, ou seja, na maneira visual e social do surdo compreender o mundo. Nesse sentindo, Strobel (2009) comenta que:

o primeiro artefato da cultura surda é a experiência visual em que os sujeitos surdos percebem o mundo de maneira diferente, a qual provoca as reflexões de suas subjetividades: De onde viemos? 0 que somos? Para onde queremos ir? Qual é a nossa identidade? (STROBEL, 2009, p. 40)

Essa convivência com pessoas surdas em diferentes níveis acadêmicos nos motivou a pensar em alguma proposta educativa que contemplasse as temáticas de gênero e sexualidade voltada para esse público. A equipe do projeto se constituiu de uma pedagoga (coordenadora do projeto), duas discentes do curso de Pedagogia Bilíngue e um discente do curso de Produção Multimídia (estes últimos atuaram como bolsistas do projeto). Os cursos nos quais a equipe participa como discente permitem que estes percebam quem é o sujeito surdo, como este vivencia sua língua e visualidade, além de como pensar materiais didáticos acessíveis. Entender que a língua "é viso-gestual e a cultura produzida por esta comunidade é visual, entre tantas outras referências que salientam a característica visual da condição de surdez" se faz essencial (LEBEDEFF, 2010, p. 178). Assim, pensar nas comunidades surdas e em como essas pessoas assimilam conhecimento é também levar em conta as "diferenças culturais, históricas e de identidade" (MIRANDA, 2001, p. 22).

Neste ínterim, ao perceber a falta de materiais didáticos em Libras sobre abuso sexual, estupro e violências, a equipe se debruçou sobre a temática. Mesmo para ouvintes, essa não é uma temática amplamente difundida, já que o assunto ainda é um tabu. Além disso, a barreira linguística, no caso dos surdos, ainda dificulta o acesso às informações.

Diante do exposto, neste artigo pretendemos principalmente relatar como se deu essa experiência. A partir desse relato, enumeramos as etapas de criação do material didático, interpretamos como os parâmetros teóricos sobre gênero e sexualidade podem permear materiais didáticos no contexto de pessoas surdas que usam a Língua de Sinais, bem como examinamos como esses conceitos podem contribuir para se produzir um material linguisticamente acessível para pessoas surdas, como será demonstrado a seguir.

\section{Metodologia}

\subsection{Contextualizando o projeto: Apontamentos sobre gênero e sexualidade}

Iniciamos esta contextualização partindo do pressuposto que entendemos que "gênero" não é um conceito fixo; é socialmente construído e pode variar a depender do grau de instrução, etnia, classe social, idade, orientação social, patamar econômico, entre outros fatores (SANTOS, 2019). A partir desse entendimento, o discurso entra como parte essencial na compreensão e na construção do significado dessa palavra, já como ao se articular este termo consolida-se a prática social e a compreensão de uma visão de mundo (FAIRCLOUGH, 2001, p. 91).

5 No primeiro seminário nacional realizado em 2001 em Caxias do Sul intitulado "Surdos: um olhar sobre as práticas em educação", a FENEIS - Regional do Rio Grande do Sul - discutiu um conjunto de ações para orientar as intervenções dos movimentos de resistência surda no contexto acadêmico. Sobre a Pedagogia da Diferença, Silva (2009) contextualizou o início de discussões acadêmicas sobre este tema. "Durante o seminário, dentre outras coisas, definiu-se em linhas gerais a formação mínima do educador surdo. Segundo a FENEIS, o educador surdo deveria ter: "conhecimentos sobre aspectos legais e suas implicações na educação dos surdos; conhecimentos sobre as políticas de inclusão e exclusão sociais e educacionais; uma visão crítica da relação da educação dos surdos com a educação especial; um conhecimento da pedagogia da diferença e as formulações que esta traz para a identidade surda; conhecimentos de projetos políticos e projetos institucionais para a surdez; condições de distinguir modelos conceituais sobre os surdos e a surdez: modelos clínicos, antropológicos e da diferença; distinguir os discursos e práticas sobre a 'deficiência auditiva' na educação, discursos e práticas clínicas; discursos e práticas sociais conhecer as implicações do disability e do estereótipo na educação dos surdos; conhecer as abordagens tradicionais do currículo na escolarização dos surdos: práticas e discursos atuais; ter uma introdução à Teoria Crítica do Currículo; conhecer sobre currículo e ideologia, linguagem, poder, cultura, política cultural; capacidade para elaborar uma proposta pedagógica e um currículo para a diferença surda. Se possivelmente as escolas tenham conselho pedagógico surdo; estabelecer uma possível posição em relação ao poder e conhecimento nas escolas para surdos (diretor, pedagogo...) para a atuação dos educadores surdos na educação $e$ na escolarização dos surdos; propor um projeto: contato incondicional professor surdo/aluno surdo; conhecer as políticas de prevenção e acompanhamento da surdez" (SILVA, 2009, p. 38) 
Assim utilizamos dos estudos de Scott (1995) e Funck (2008) dissertado nos estudos de Santos (2019) para pensar o conceito de gênero além da dicotomia de sexo ou diferença sexual. Sem usar termos como "diferença sexual" e "sexo", concordamos com as feministas anglo-saxãs que determinam gênero incorporando características sociais, sendo este diferente de sexo.

Trazemos também os estudos de Butler (2015) que questiona as modelagens atuais das identidades de gênero. Ela explica como a sociedade estrategicamente e de maneira taxativa vê os corpos, sem nenhum tipo de significação aprofundada. Santos (2019, p. 71) explica que Butler entende que, quando o discurso limita o que o corpo pode significar, isso reflete os tabus envolvendo posturas e performatividades, definindo o que pode constituir o corpo e o que não pode.

Quando falamos de performatividade de gênero, também trazemos os pensamentos de Butler (2015), que explica que esta é a maneira que a sociedade conservadora encontra para disciplinar o gênero. Ou seja, 'qualquer 'corpo gênero' performativo sugere que ele não tem um 'status ontológico' separado de suas outras práticas sociais" (BUTLER, 2015, p. 234-235).

Partindo desse pressuposto de que gênero e sexualidade possuem fronteiras que barram o socialmente hegemônico, estes também rompem simbolicamente as demarcações do aceitável (SANTOS, 2019). Pensando em pessoas surdas, que também destoam do padrão de "normalidade" e, além disso, possuem uma língua diferente, entendemos que o entendimento dos conceitos de gênero e sexo também não são aproximadas de suas realidades.

Ferreira (2008) traz em seus estudos a vulnerabilidade de pessoas com deficiência (nesse estudo inclui pessoas surdas) ao risco de violência sexual, já que são tidas como invisíveis socialmente além do isolamento antagônico à postura de denúncia, o que está atrelado à falta de apoio familiar e escolar. Além disso, quando se pensa que, por exemplo, uma pessoa surda é um ser obrigatoriamente não dotado de desejos sexuais, as situações envolvendo abuso e violência sexual são negligenciadas e o acesso à educação sexual também é omitido. Ainda, para pessoas surdas, há a barreira da língua, já que pessoas surdas usuárias da Libras precisam entender conceitos em sua língua materna. 0 caminho que a informação leva para chegar a uma pessoa surda é mais longo do que para uma pessoa ouvinte, já que percebemos que a sociedade não é acessível à língua e à cultura surda.

Com tais conceitos em mente, propusemos uma metodologia que unisse o aparato teórico no qual acreditamos com uma proposta que atingisse nosso público alvo, a saber, os surdos usuários da Língua Brasileira de Sinais.

\subsection{Proposta metodológica e aplicação do projeto}

A primeira proposição do grupo foi pensar na criação de palestras em Libras a serem realizadas em duas escolas da Grande Florianópolis, que contemplam alunos e alunas surdos. Contudo, em virtude dos calendários das escolas, estas não conseguiram encaixar essa atividade de extensão com seus alunos. Assim, junto com a diretoria dessas escolas, decidimos criar um material em vídeo e impresso, para ser exibido para os alunos e permanecer na escola como material de consulta.

Escolhemos como temáticas "Educação sexual" e "Educação sexual para prevenir abusos", depois de pesquisas sobre as temáticas não tão debatidas com os e as discentes em conjunto com a equipe pedagógica das duas escolas. Fomentamos uma discussão em como desconstruir pré-conceitos acerca desses assuntos. Para isso, contamos com um acervo de materiais visuais e textuais com linguagem simples para facilitar o acesso ao público surdo.

"O Planeta eu - conversando sobre sexo", escrito por Liliana Lacocca e Michele Lacocca, e "Pipo e Fifi", escrito por Carolina Arcari, foram escolhidos como fontes de pesquisa, tendo como justificativa o uso da linguagem simplificada ao se explicar temáticas relacionadas a sexualidade e gênero. Pensando em como livros para a infância podem fomentar pesquisa e instigar reflexões, pensamos que tais livros têm potencial educativo e são importantes artefatos culturais produzidos para a infância. No caso das pessoas surdas, em virtude da aquisição tardia da língua, de conceitos desconhecidos e pela quantidade de imagens descritivas da temática, preferimos utilizar tais livros como artefatos culturais que "expressam formas de ser, entre outros elementos que constituem identidades" (FILHA, 2014, p. 159).

Os livros didáticos, nesse sentido, podem produzir significados, evidenciando como esses leitores podem compreender suas relações e a maneira que vivem sua sexualidade. Giroux e McLaren (1995) ressaltam que há pedagogia em qualquer lugar em que se produz conhecimento. Assim:

os vários contextos educacionais da sociedade bem como os mais diferentes artefatos culturais, como cinema, mídia, revistas, livros, brinquedos, entre outros, expressam e fazem circular discursos que produzem as subjetividades. Entender os livros como artefatos culturais que expressam pedagogias é uma tarefa que nos leva a analisar os próprios textos e ilustrações para, contudo, questionar conceitos e também promover a reflexão e a autorreflexão dos leitores e leitoras. (FILHA, 2014, p. 155) 
A partir de pesquisa prévia com tais materiais didáticos, decidimos em grupo discutir sobre os corpos, sobre as sexualidades, violência sexual e como nos proteger destas, em Libras.

Pensamos também na articulação entre ensino, pesquisa e extensão, já que o projeto se tornou interdisciplinar, por integrar diferentes áreas do conhecimento. A presença de alunos bolsistas incentiva a produção do conhecimento e oportuniza às pessoas surdas a aquisição de conhecimento. Tais atividades foram entendidas como atividades de cunho acadêmico, científico e cultural, visando a complementação da formação do aluno e a indissociabilidade entre ensino, pesquisa e extensão.

Sobre os bolsistas participantes da equipe, como já mencionado, estes são discentes dos cursos de Graduação em Pedagogia Bilíngue e Tecnólogo em Produção Multimídia. Ambos os cursos possuem um eixo voltado ao audiovisual com unidades curriculares como Libras - Projetos Interdisciplinares, Infâncias, aprendizagens e subjetividades, Linguagem e Estética Audiovisual e Técnicas de Produção Audiovisual. Tais alunos puderam usar seus conhecimentos para, a partir do estudo destes materiais didáticos juntamente com a leitura de artigos científicos sobre a temática, criaros materiais propriamente ditos.

Para manter a equipe atenta aos prazos, reuniões semanais foram realizadas. Os bolsistas, no entanto, tiveram bastante liberdade para executarem as atividades, cumprindo o cronograma e executando as atividades com maestria. 0 primeiro material desenvolvido e impresso foi um folder cujo tema foi a Educação Sexual. 0 folheto foi diagramado pelos alunos, além de todas as ilustrações ali dispostas também terem sido criadas pelos mesmos. 0 folder abordou conhecimentos como puberdade, mudanças no corpo, órgãos sexuais, prevenção da gravidez e doenças sexualmente transmissíveis (DSTs). As Figuras 1 e 2 demonstram como o folder foi organizado, como as imagens foram dispostas e qual o formato físico do material.

Figura 1: Frente do folder criado

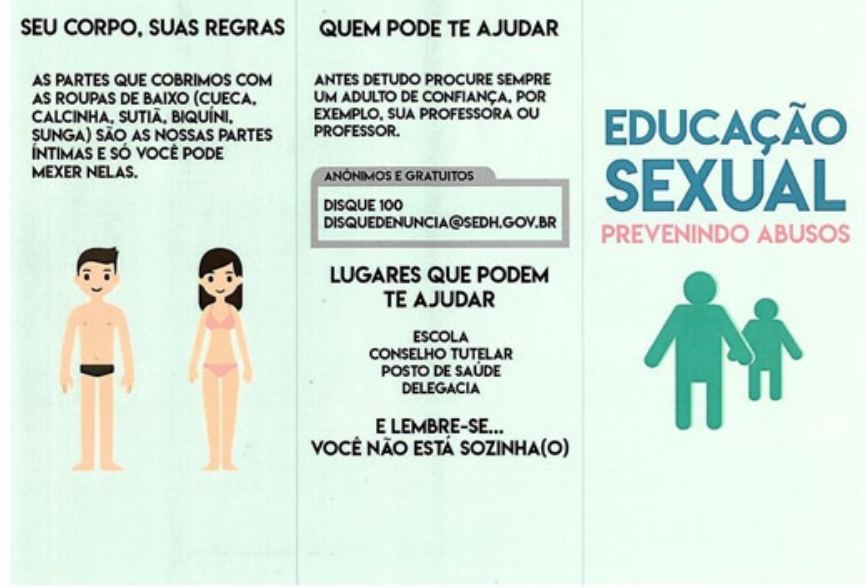

Fonte: Produção original dos autores.

Figura 2: Parte interna do folder criado

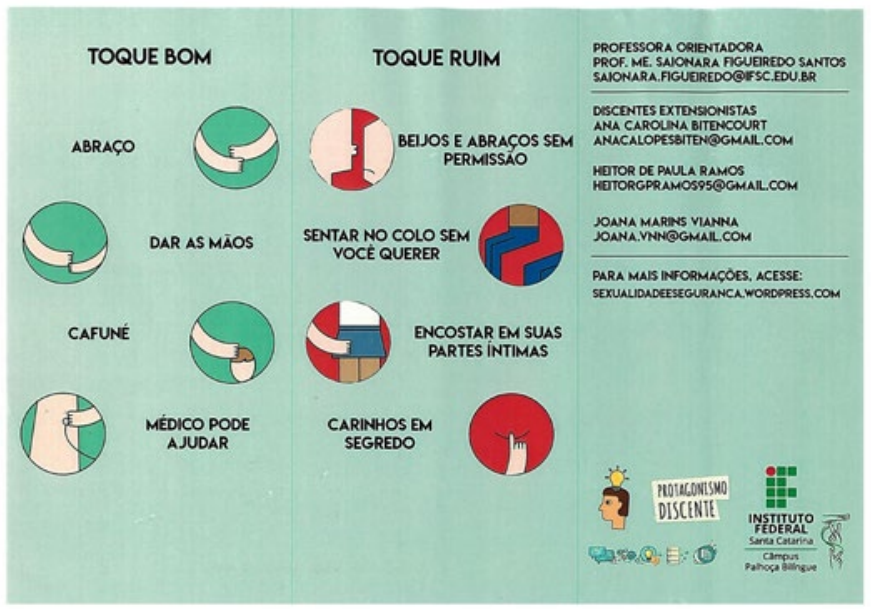


Além dessa mídia, as duas palestras programadas foram realizadas em vídeo como material didático. 0 grupo de pesquisa teve a oportunidade de desenvolver a temática em Libras usando roteiros organizados previamente, abordando com clareza as temáticas escolhidas. Os recursos visuais utilizados no vídeo se dividiram entre os temas "Corpo e sexualidade" e "Prevenção de abusos".

Cada vídeo-palestra teve duração de 30 minutos; nestes, os temas foram explicados de maneira detalhada, em Libras. Houve o uso de imagens para melhor visualização do conteúdo. Trabalhamos de maneira simplificada conceitos abordados na parte teórica deste relato de experiência. A edição dos vídeos já foi realizada e estamos em processo de disponibilização do conteúdo.

0 formato de linguagem utilizado no vídeo escolhido pelo grupo foi o de Palestra, num tom mais informal, para aproximar a mensagem dos alunos jovens. A Figura 3 demonstra nossas escolhas no que se refere ao layout do vídeo, bem como a proposta visual das sinalizantes e dos recursos imagéticos utilizados no contexto da temática da palestra.

\section{Figura 3: Alunas bolsistas em processo de gravação}
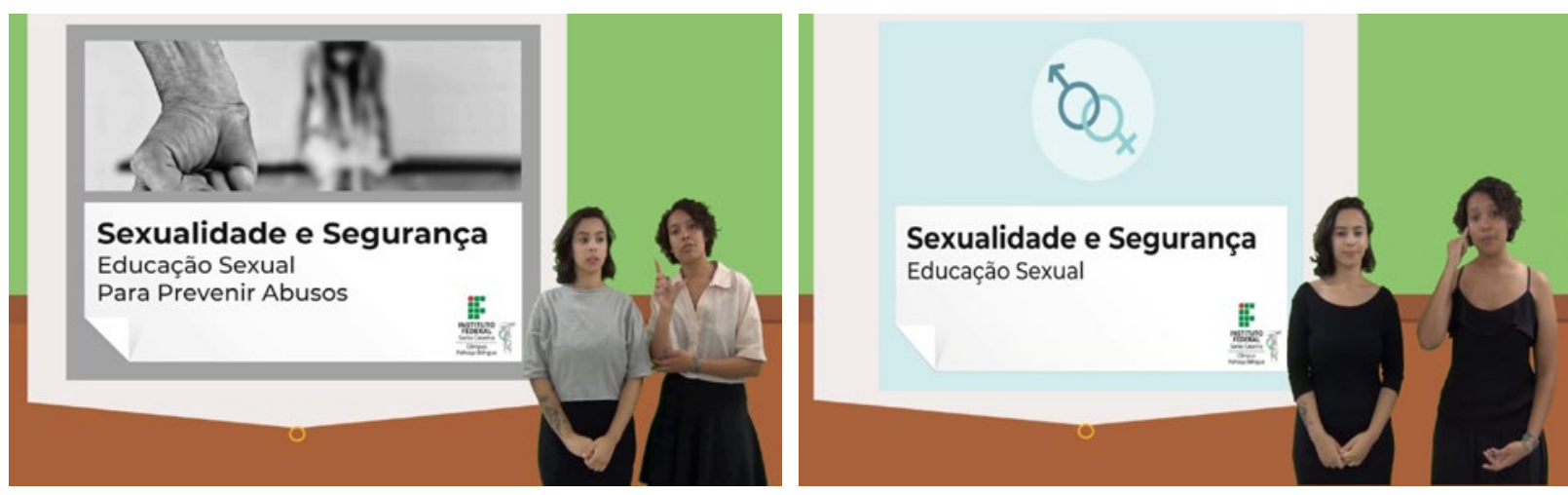

Fonte: Imagens originais dos autores

\section{Resultados e discussão}

Em primeiro plano, a própria equipe se beneficiou das vivências proporcionadas pelo projeto, pois experienciaram o fazer docente e aproveitaram o maior contato com pessoas surdas em idade escolar. Além disso, o público surdo também desfrutou das ações propostas pelo projeto, já que obtiveram mídias pensadas e concebidas na Libras e focadas neste público alvo.

Desenvolvemos uma proposta de palestras, inserindo dentro do formato de vídeo a proposta de rodas de conversas, aproveitando as temáticas abordadas. 0 folder serviu como cartilha e foi distribuído às escolas parceiras, assim como os vídeos já estão em processo de divulgação para a comunidade externa.

A partir das conversas realizadas com as escolas, ficou claro que as pessoas surdas possuem defasagem de conhecimento relacionado a gênero e sexualidade. Isso corrobora com o abordado teoricamente nesse artigo (FERREIRA, 2008), onde é perceptível o quanto pessoas que não estão nos padrões de normalidade (incluindo pessoas surdas) são invisibilizadas, desconhecem temáticas específicas relacionadas a gênero e sexualidade, bem como não dialogam com suas famílias sobre violência sexual.

Essa falta de diálogo entre pessoa surda e família ou pessoa surda e escola se dá principalmente pelo entrave linguístico. Sem o domínio da língua, tanto família quanto escola não conseguem construir a ponte de confiança necessária para que pessoas surdas se sintam à vontade para conversar sobre o assunto. Nesse ínterim, a escola deve ser um dos espaços que podem proporcionar um ambiente seguro, acessível (linguisticamente também) e saudável de debate e troca, já que, na grande maioria dos lares, os pais são ouvintes e não são fluentes em Libras.

Por fim, este projeto procurou aprofundar e aplicar esses conhecimentos produzidos no ensino através da pesquisa aplicada. Dessa maneira, aproximou professores e discentes, além de produzir resultados como artigos acadêmicos, socializando os conhecimentos e resultados apreendidos. A realização desse projeto é uma maneira de aproximar a comunidade do entorno do câmpus com a temática. Os resultados do projeto e os conhecimentos produzidos pelos alunos poderão ser compartilhados através de seminários, oficinas, eventos culturais, website e redes sociais.

O fazer educativo não é nem deve ser engessado, estando nestas práticas de pesquisa e socialização de resultados propostas possíveis para assegurar formação e aquisição de conhecimentos à comunidade surda. 


\section{Referências}

BUTLER, J. Problemas de Gênero-Feminismo e Subversão da Identidade-Col. Sujeito \& História, (2015).

FAIRCLOUGH, N. A Análise Crítica do Discurso e a mercantilização do discurso público: as universidades. In: MAGALHÃES, Célia. (Org.). Reflexões sobre a Análise Crítica do Discurso. Belo Horizonte: Faculdade de Letras, UFMG, 2001. p. 31-82.

FERREIRA, W. B. (2008). Vulnerabilidade à violência sexual no contexto da escola inclusiva: reflexão sobre a invisibilidade da pessoa como deficiência. Revista Iberoamericana sobre Calidad, Eficacia y Cambio en Educación, 6(2), 120-136.

FILHA, C. X. (2014). Gênero, corpo e sexualidade nos livros para a infância. Educar em Revista, 1(53), 153169.

FUNCK, S. Discurso e identidade de gênero. Desvendando discursos: conceitos básicos. Florianópolis: EDUFSC, 2008 ( $p$; 183-195).

GIROUX, Henry A.; MCLAREN, Peter L. Por uma pedagogia crítica da representação. In: SILVA, Tomaz Tadeu da; MOREIRA, Antônio Flávio (Orgs.). Territórios contestados: o currículo e os novos mapas políticos e culturais. Petrópolis: Vozes, 1995.

KLEIN, M.; DE PAULA FORMOZO, D. Gênero e surdez. Reflexão e Ação, 2007, 15.1: 100-112.

LEBEDEFF, T. B. (2010). Aprendendo a ler "com outros olhos": relatos de oficinas de letramento visual com professores surdos. Cadernos de Educação, 36, 175-190.

MIRANDA, W. de 0. Comunidade dos surdos: olhares sobre os contatos culturais. 2001. Dissertação (Mestrado em Educação) - Universidade Federal do Rio Grande do Sul. Porto Alegre.

SANTOS, S., F. A construção discursiva de identidades de gênero de tradutores e intérpretes de libras não heteronormativos. Tese de doutorado em Universidade Federal de Santa Catarina. 2019.

SCOTT, J. Gênero: uma Categoria Útil de Análise Histórica. Educação e Realidade. 20 (2), p.71-99, 1995.

SILVA, V. D. (2009). A política da diferença: educadores-intelectuais surdos em perspectiva. Tese de Doutorado em Educação. UFSC, Florianópolis, 2009.

STROBEL, K. (2009). História da educação de surdos. Universidade Federal de Santa Catarina. Florianópolis 